\title{
Obesity-Related Hormones in Low-Income Preschool-Age Children: Implications for School Readiness
}

\author{
Alison L. Miller ${ }^{1,2}$, Carey N. Lumeng ${ }^{3,4}$, Jennifer Delproposto ${ }^{3}$, Brian Florek ${ }^{2}$, Kristin Wendorf ${ }^{2}$, and \\ Julie C. Lumeng $2,3,5$
}

\begin{abstract}
Mechanisms underlying socioeconomic disparities in school readiness and health outcomes, particularly obesity, among preschool-aged children are complex and poorly understood. Obesity can induce changes in proteins in the circulation that contribute to the negative impact of obesity on health; such changes may relate to cognitive and emotion regulation skills important for school readiness. We investigated obesity-related hormones, body mass index (BMI), and school readiness in a pilot study of low-income preschoolers attending Head Start (participating in a larger parent study). We found that the adipokine leptin was related to preschoolers' BMI $z$-score, the appetite-regulating hormones ghrelin and glucagon-like peptide l (GLP-1), and pro-inflammatory cytokines typically associated with early life stress; and that some of these obesity-related biomarkers were in turn related to emotion regulation. Future work should evaluate how obesity may affect multiple domains of development, and consider modeling common physiological pathways related to stress, health, and school readiness.
\end{abstract}

${ }^{1}$ Department of Health Behavior and Health Education, School of Public Health, University of Michigan

${ }^{2}$ Center for Human Growth and Development, University of Michigan ${ }^{3}$ Department of Pediatrics and Communicable Diseases, University of Michigan

${ }^{4}$ Department of Molecular and Integrative Physiology, University of Michigan

${ }^{5}$ Human Nutrition Program, Department of Environmental Health Sciences, School of Public Health, University of Michigan

Address correspondence to Alison L. Miller, 1415 Washington Heights, SPH 1, Room 3718, University of Michigan, Ann Arbor, MI 48109-2029; e-mail: alimill@umich.edu
Cognitive and emotion regulation skills are critical for school readiness (Blair, 2002; Liew, 2012). Obesity and obesity-related biology have been associated with impaired cognition, particularly executive functioning (Smith, Hay, Campbell, \& Trollor, 2011), and also emotion regulation difficulties-(e.g., depression; Taylor \& MacQueen, 2010). Such associations are the focus of a burgeoning literature in animals and older adults (e.g., Carlini, Ghersi, Schioth, \& de Barioglio, 2010; Perry \& Greig, 2004; Yamada et al., 2011). Childhood obesity is associated with poor school performance (Datar \& Sturm, 2006; Gable, Krull, \& Chang, 2012), yet developmentalists have not considered possible biological mechanisms linking obesity and school readiness. We explore the obesity-school readiness pathway in a small sample of low-income preschoolers, examining whether obesityrelated hormonal changes are present in children this young; associated with other biomarkers relevant for cognition and mood regulation; or associated with school readiness skills, specifically emotion regulation, and effortful control. We present results of a pilot study with the goal of building a conceptual framework to examine the complex ways in which biology and health contribute to school readiness. Understanding such processes in low-income preschoolage children is important, given this population is at risk both for obesity (Feese et al., 2003) and poor school readiness (Blair \& Diamond, 2008; Evans \& Rosenbaum, 2008; Kaiser, Hancock, \& Cai, 2000; Najman et al., 2009). Low-income children also experience high stress (Evans \& English, 2002), which may be a common pathway adversely affecting school readiness, obesity, and health (Dallman et al., 2003; Gundersen, Mahatmya, Garasky, \& Lohman, 2011). 
Two recent developments are germane to our discussion. First, it is increasingly well-recognized that the hormones regulating satiety and food intake (and thus altered in obesity) also affect cognition, learning, and memory (Chowen \& Argente, 2011; Diano et al., 2006; Harvey \& Ashford, 2003; Harvey, Shanley, O'Malley, \& Irving, 2005). Much work is in animal models, but human studies also suggest that obesity is associated with cognitive deficits (Elias, Sullivan, Wolf, \& D'Agostino, 2003; Fergenbaum et al., 2009; Y. Li, Dai, Jackson, \& Zhang, 2008; Sellbom \& Gunstad, 2012; Smith et al., 2011). Hormones controlling metabolism may also activate receptors in brain areas relevant for learning and memory, such as the hypothalamus and hippocampus (Diano et al., 2006; Harvey \& Ashford, 2003; Harvey et al., 2005; McNay, 2007; Squire, 1992). Some hypothesize that obesity-related hormonal changes affect cognitive function, in turn affecting response to cognitive-behavioral obesity treatments (Hoeman, 2007; Lokken, Boeka, Austin, Gunstad, \& Harmon, 2009; Parisi et al., 2010; Riggs, Spruijt-Metz, Sakuma, Chou, \& Pentz, 2010). A gap in the literature relevant for educators is whether such associations exist in young children. Second, adipose tissue (i.e., fat) is recognized to be more than just an inert tissue storing excess energy. Rather, it is very metabolically active, producing multiple substances (e.g., adipokines such as leptin; pro-inflammatory cytokines) that affect many bodily functions, including cognition (Farr, Banks, \& Morley, 2006; Oomura et al., 2006; Paz-Filho, Wong, $\&$ Licinio, 2010) and mood (Kim, Jung, Myint, Kim, \& Park, 2007; Maletic et al., 2007; Soczynska et al., 2010; Yamada et al., 2011). Indeed, obesity and mood disorders often cooccur (for many reasons, but possibly biologically mediated; Luppino et al., 2010; Soczynska et al., 2010). Taking a broad perspective, we use the word "hormone" to encompass various proteins that circulate in the blood and communicate between cells, including cytokines (which modulate inflammatory responses), adipokines (fat-derived proteins), and factors produced by endocrine organs such as the gastrointestinal system.

Children growing up poor are at risk for early obesity (Feese et al., 2003) and thereby also for long-term negative and systemic physiological changes due to obesity-related biology (Kyrou, Chrousos, \& Tsigos, 2006). We know little about how these mechanisms operate in young children. Our conceptual model (Figure 1) illustrates hypothesized links among stress, obesity, and school readiness. We examine pathways from obesity and gutderived hormones (ghrelin; glucagon-like peptide 1 [GLP-1]) to pro-inflammatory cytokines (TNF $\alpha$; IL-6) and adipokines (leptin), and between these biomarkers and school readiness skills. We review below literature establishing associations among obesity, obesity-related physiological changes, and learning, memory, and emotion regulation skills that have

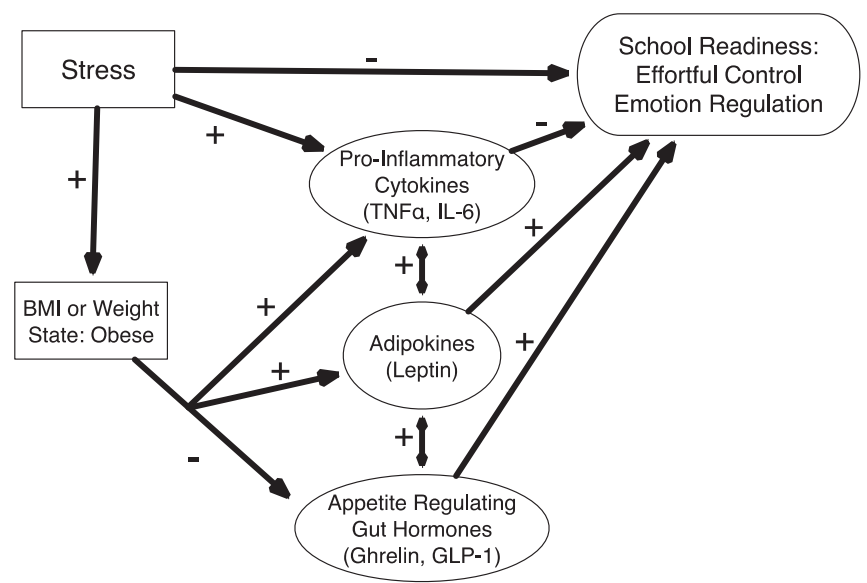

Fig. 1. Conceptual model.

implications for school readiness, noting where more research is needed.

\section{Hormones That Drive Eating Behavior Also Affect Cognition and Possibly Mood}

Eating behavior refers to both how much and what type of food someone eats. Hunger and satiety cues affect the amount of food eaten, whereas taste perception and the hedonic impact of substances such as sugar and fat drive the types of foods eaten. This oversimplifies a very complex and as yet poorly understood process, however. A detailed network of signals communicates information between the central nervous system, gastrointestinal tract (extending from mouth to rectum), and fat tissue. The gastrointestinal system produces "gut" hormones that send signals to the brain, affecting satiety and metabolism. We examine two of these, ghrelin and glucagon-like peptide l (GLP-1). Ghrelin is a hormone made in the stomach and induces hunger by signaling to the hypothalamus. Obesity is associated with lower ghrelin levels and abnormal changes in ghrelin after a meal. Ghrelin also activates and stimulates brain regions relevant for learning: ghrelin administration to rodents increased long-term memory and learning of spatial tasks (Atcha et al., 2009; Carlini et al., 2008; Carlini et al., 2010; Steiger, Dresler, Schussler, \& Kluge, 2011). Ghrelin may also relate to mood regulation and the dopaminergic reward system (Andrews, 2011); administering ghrelin to mice protected them from depressive and anxious responses when put under stress (Lutter et al., 2008). The few studies of humans are more mixed, with ghrelin levels found to increase under acute stress (Raspopow, Abizaid, Matheson, \& Anisman, 2010), or to be unrelated to depression and anxiety symptoms (Lawson et al., 2012).

GLP-1 is a hormone produced by cells in the intestine and regulates satiety. Treatment with GLP-1 promotes satiety and decreases energy intake (Flint, Raben, Astrup, \& Holst, 1998; Nauck, Vilsboll, Gallwitz, Garber, \& Madsbad, 2009). 
Like ghrelin, the receptors sensing GLP-1 in the brain may mediate more than just appetite. Mice deficient in the GLP-1 receptor have learning and memory deficits (Abbas, Faivre, \& Holscher, 2009; During et al., 2003; Porter, Kerr, Flatt, Holscher, \& Gault, 2010). Further, their stress response is blunted (MacLusky et al., 2000).

Thus, there is overlap between hormones that regulate food intake, cognitive processes, stress regulation, and mood. One could imagine that these pathways co-evolved to confer evolutionary advantages: for an animal with low fat mass, hormonal cues driving hunger would be beneficial if they also increased cognitive abilities improving food-seeking behavior, and enabled the animal to cope with stress. Conversely, it is possible that an animal with fat stores (as with obesity) might have a "dulling" of learning and cognition, as its need to acquire food is less urgent. We next consider how fat tissue itself may contribute.

\section{Fat Tissue Produces Substances That Affect Brain Function}

Fat tissue functions to store nutrients in times of plenty and release them during fasting and when extra energy is required (e.g., illness, exercise). In obesity, adipose tissue is massively expanded as nutrient uptake is in excess of energy expenditure. In both lean and obese states, adipose tissue produces substances that communicate with multiple tissues and organ systems, including the brain, to regulate metabolism. These fat-derived hormones are referred to as adipokines. Adipokines circulate throughout the bloodstream where they can affect the function of tissues important in metabolic control. For example, the adipokine leptin is made exclusively by fat cells (adipocytes) and provides signals to the brain that serve to gauge the amount of fat stored in the body. Adipokine secretion is regulated by stress, hunger, and circadian signals. Adipokines have received much attention since they are altered in obese children and adults (e.g., Zhang et al., 2011) and contribute to the maintenance of an obese state and development of associated adverse health effects (e.g., cardiovascular disease, type 2 diabetes). Leptin levels relate to obesity in older children (Clayton et al., 1997), but few have examined leptin-weight status associations in preschoolers (Salbe, Nicolson, \& Ravussin, 1997).

Leptin was one of the first adipokines identified from obese mice that have a genetic loss of leptin and display profound overeating (Halaas et al., 1995). Its levels in the blood increase with increasing fat (Farooqi \& O'Rahilly, 2009). Leptin affects brain signals that control satiety and nutrient metabolism; the inability of receptors in the hypothalamus to sense leptin is associated with dramatic increases in food intake and obesity. Most obesity research focuses on leptin in the hypothalamus and appetite regulation, but receptors for leptin are found throughout the brain. The role of leptin in other brain areas is less clear, but may operate to influence other brain functions. For example, leptin regulates neurons (Morrison, 2009) in brain regions involved with memory and reward. Leptin has thus been hypothesized to play a role in motivation (Davis, 2010) and mood regulation (Lutter $\&$ Elmquist, 2009), particularly depression (Lawson et al., 2012; Taylor \& MacQueen, 2010). Leptin has also been proposed as influencing executive functioning skills (e.g., working memory; Chowen \& Argente, 2011; Paz-Filho et al., 2010). In older adults, leptin has shown both positive and negative associations with cognitive function (Gunstad et al., 2008; Labad et al., 2012; Morrison, 2009). In mice, shortterm leptin infusion may improve memory and learning (Farr et al., 2006; Oomura et al., 2006) and leptin is important for brain development (Ahima, Bjorbaek, Osei, \& Flier, 1999). The role of leptin in obesity is complex, considering obesity is associated with chronically elevated leptin but also with limited cognitive function. For example, mice lacking leptin receptors are obese and also demonstrate learning deficits (X. L. Li et al., 2002). Given that executive function deficits have been identified in obese compared to normal-weight children (Lokken et al., 2009; Parisi et al., 2010; Smith et al., 2011), leptin may be an important mechanism to investigate in this regard.

In addition to adipokines, fat tissue releases proteins into the circulation involved in inflammation, known as cytokines. It is not well understood why fat tissue makes these factors; however, in obesity the release of cytokines that promote inflammation (pro-inflammatory cytokines) is increased. The release of these cytokines from fat in obese individuals contributes to a state of low-grade inflammation observed with chronic obesity. The influence of chronic inflammation in obesity on mood regulation is unclear; however, low-grade inflammation is also observed in some mood disorders (Currier $\&$ Nemeroff, 2010; Maes, 1999; Soczynska et al., 2010). The ability of these cytokines to induce inflammatory responses is thought to be partially responsible for associations between obesity and poor health outcomes (Gregor \& Hotamisligil, 2011). The obesity-inflammation link may also be relevant for cognition, given that systemic inflammation may negatively affect memory and learning (Moore, Wu, Shaftel, Graham, \& O'Banion, 2009; Shaw, Commins, \& O'Mara, 2001, 2005). This observation becomes particularly important because obese children as young as age 3 years can have elevations of inflammatory markers in their bloodstream, suggesting that life-long changes in inflammation could promote adverse health consequences of obesity, as well as potentially impair learning, memory, and mood regulation (Skinner, Steiner, Henderson, \& Perrin, 2010).

\section{Current Gaps in Knowledge}

Clearly much remains to be understood regarding potential physiologic links between obesity-associated hormonal 
changes and the learning, cognition, and emotion regulation skills critical for school readiness. Documenting how these hormones relate to obesity in early childhood is a first step, as most work in this area has been conducted in adults or animals. Associations between ghrelin and GLP-1 levels and obesity in pre-pubertal children are inconsistent, and weight loss can alter hormone levels (Gallistl, Sudi, Aigner, \& Borkenstein, 2001; Martos-Moreno et al., 2011; Reinehr, de Sousa, \& Roth, 2007; Roth \& Reinehr, 2010; Shin et al., 2008). Elevated leptin is associated with obesity in pre-pubertal children (Araki et al., 2008; Hosking et al., 2010; Jeffery et al., 2008; MartosMoreno et al., 2011; Metcalf et al., 2009; Reinehr, Kratzsch, Kiess, \& Andler, 2005), though most studies focus on children aged 7 years or older. Almost no studies have examined proinflammatory cytokines in young children, yet recent findings of other inflammatory changes in obese preschoolers (Skinner et al., 2010) suggests we should examine such phenomena early, particularly given high rates of obesity even in early childhood (Feese et al., 2003).

In this pilot investigation of low-income preschoolers, we sought to examine: (l) whether higher body mass index (BMI) was associated with lower levels of gutderived hormones (ghrelin; GLP-1), higher leptin, and higher pro-inflammatory cytokines (TNF $\alpha$; IL-6); (2) whether proinflammatory cytokines were related to leptin and gut-derived hormones relevant for appetite regulation (ghrelin and GLP1), in an effort to identify early obesity-related inflammation; and (3) whether obesity-related hormones were related to school readiness (emotion regulation, effortful control) or home environment stress. Demonstrating such associations would provide support for further investigating biological mechanisms by which obesity could affect school readiness.

\section{METHOD}

\section{Participants and Recruitment}

Participants were 34 Head Start preschoolers enrolled in a larger study of stress, eating behavior, and obesity (Lumeng, 2009). Children and primary caregiver/legal guardian (usually mother) were compensated $\$ 90$ for participating in the parent study. Inclusion criteria were: Head Start enrollment; parent/child speak English; parent <4-year college degree; child born at $\geq 35$ weeks gestation with no significant perinatal/neonatal complications, food allergies, or serious medical problems affecting appetite/eating; not in foster care; and having no medical problems or using any medications that affect cortisol.

Participants were recruited for the parent study through Head Start classroom open houses. Families for whom parent study data collection was complete were contacted by phone and invited to participate in the current pilot study (requiring a serum sample by finger stick from the child). Compensation for pilot study participation was $\$ 50$. Agreement to participate exceeded $90 \%$. Studies were approved by the University of Michigan Institutional Review Board and written informed consent was obtained.

Our pilot sample was relatively equally divided among obese $(n=10)$, overweight $(n=10)$, and nonoverweight $(n=14)$ groups. Using Centers for Disease Control growth charts, BMI $z$-scores (BMIz) for age and sex were calculated and child weight status was categorized as obese (BMI $\geq 95$ th percentile), overweight (BMI $\geq 85$ th, but $<95$ th percentile), and nonoverweight (BMI $\geq 50$ th, but $<85$ th percentile; nonoverweight children were limited to those with BMI $z$-score $\geq 0$ because few parent study children had BMI $z$-score $<0$, and many of those were underweight, which may suggest other medical problems). Families of obese and overweight children were contacted in order of parent study enrollment to participate in the pilot. Nonoverweight children were identified as matched controls based on sex, race, and age, and also recruited in parent study order.

The pilot sample was demographically comparable to the parent study: $56 \%$ male $(n=19) ; 73.5 \%$ Caucasian $(n=25$; others were biracial). Child age ranged from 3.17 to 4.94 years $(M=4.05, S D=0.57)$. There was no association of BMIz with child sex, race, or age. Income-to-needs ratio ranged from 0.60 to 0.81 (poverty $=1.0$ ), confirming this was a poverty sample.

\section{Procedure and Measures}

The parent study involved sampling child saliva to measure diurnal cortisol; measuring weight and height; gathering questionnaires about demographics, home environment, temperament, emotion regulation, eating, and diet; and observing child behavior. For the pilot, trained research assistants conducted finger sticks on children to obtain hormone levels from serum. We report here on serum markers, questionnaire data, and anthropometrics (BMI). Cortisol data are not reported.

\section{Biomarkers}

A fasting serum sample was obtained in the morning; about $0.5 \mathrm{ml}$ of blood was drawn. The sample was assayed for ghrelin, GLP-1 (R\&D Systems, Minneapolis, MN, USA), leptin, and pro-inflammatory cytokines TNF $\alpha$ and IL-6 using multiplex analysis from serum (Luminex, Austin, TX, USA). All biomarkers were quantitated from a single sample of 200-300 $\mu$ l of serum. Samples were analyzed in triplicate and quantitated based on standard curves.

\section{Parent Reports}

Parents completed the Emotion Regulation Checklist (Shields $\&$ Cicchetti, 1998) to assess Emotion Regulation (8 items; $\alpha=.65$ ) and Negative Lability (16 items; parent study $\alpha=.82$ ) 
Table 1

Descriptive Statistics for Gut-Derived Hormones, Adipokines, and Pro-Inflammatory Cytokines $(n=32$; all measures in $\mathrm{pg} / \mathrm{ml})$

\begin{tabular}{lrrrr}
\hline \hline & Min & Max & \multicolumn{1}{c}{ M } & \multicolumn{1}{c}{ SD } \\
\hline Ghrelin & 0.51 & 26.83 & 9.67 & 5.44 \\
GLP-1 & 104.29 & 509.49 & 351.91 & 93.99 \\
Leptin & 206.08 & 824.81 & 438.73 & 145.26 \\
TNF $\alpha$ & 1.93 & 9.93 & 5.84 & 1.93 \\
IL-6 & 2.08 & 7.88 & 4.22 & 1.36 \\
\hline \hline
\end{tabular}

and the Effortful Control subscale of the Child Behavior Questionnaire-Short Form (12 items; $\alpha=.76$; Putnam \& Rothbart, 2006). Parents completed the 15-item CHAOS scale (Matheny, Wachs, Ludwig, \& Phillips, 1995) to assess home environment stress (e.g., disorganization; $\alpha=.80$ ).

\section{Analysis Plan}

We calculated descriptive statistics for serum markers (Table 1; 2 statistical outliers removed). We used Pearson correlations and partial correlations (covarying age as needed) to examine associations among gut-derived hormones, adipokines, pro-inflammatory cytokines, BMIz, parentreported variables, and demographics (child age, sex, race, income-to-needs ratio).

\section{RESULTS}

Older children were rated as having less home chaos $(r=-.33)$, less lability $(r=-.44)$, better emotion regulation $(r=.62)$ and better effortful control $(r=.47, p s<.05)$. Thus, we covaried age in analyses involving these variables. There were no race/ethnicity or income differences. Leptin was higher in girls (girls' $M=637.10 \mathrm{pg} / \mathrm{ml}$; boys' $\mathrm{M}=401.10 \mathrm{pg} / \mathrm{ml}$ ), consistent with other studies (Hassink et al., 1996; Nagy et al., 1997). There were no associations between biomarkers and other demographic variables.

Associations of BMIz and serum markers are shown in Table 2. BMIz was not associated with ghrelin, GLP-1, TNF $\alpha$, or IL-6. Leptin was positively associated with BMIz.

Positive associations were seen among pro-inflammatory cytokines, leptin, and gut hormones (Table 2). TNF $\alpha$ and IL-6 were strongly correlated, as were IL- 6 and GLP-1. Leptin was associated with GLP-1, TNF $\alpha$, and IL-6; pro-inflammatory cytokines TNF $\alpha$ and IL- 6 were associated with gut hormones, most strongly with GLP-1.

Table 3 presents biomarker, school readiness, and chaos correlations (covarying age). We found evidence for the pathway from obesity-related biomarkers to emotion regulation, but not for effortful control or home chaos. Leptin and TNF $\alpha$ were associated with better emotion regulation and less negative lability (IL-6, GLP-1 marginally associated in this
Table 2

Correlations Among Biomarkers and BMIz-score $(n=32)$

\begin{tabular}{lccccc}
\hline \hline & BMIz & Ghrelin & GLP-1 & Leptin & TNF $\alpha$ \\
\hline Ghrelin & .06 & & & & \\
GLP-1 & .06 & $.41^{*}$ & & & \\
Leptin & $.44^{* *}$ & -.03 & $.48^{* *}$ & & \\
TNF $\alpha$ & .05 & $.38^{*}$ & $.93^{* * *}$ & $.49^{* *}$ & \\
IL-6 & .09 & $.34^{\dagger}$ & $.85^{* * *}$ & $.56^{* *}$ & $.90^{* * *}$ \\
\hline \hline${ }^{* * *} p<.001 .{ }^{* *} p<.01 .{ }^{*} p<.05 .{ }^{\dagger} p<.10$. & & &
\end{tabular}

Table 3

Partial Correlations: Biomarkers and School Readiness, Home Environment Stress ( $d f=29$; covarying age)

\begin{tabular}{lcccc}
\hline \hline & \multicolumn{3}{c}{ School readiness } & Homestress \\
\cline { 2 - 4 } & $\begin{array}{c}\text { Effortful } \\
\text { control }\end{array}$ & $\begin{array}{c}\text { Negative } \\
\text { lability }\end{array}$ & $\begin{array}{c}\text { Emotion } \\
\text { regulation }\end{array}$ & Chaos \\
\hline Biomarker & & & & \\
Ghrelin & -.13 & .14 & .21 & -.01 \\
GLP-1 & -.10 & -.21 & $.31 \dagger$ & -.23 \\
Leptin & .15 & $-.48^{* *}$ & $.36^{*}$ & -.21 \\
TNF $\alpha$ & .02 & $-.37^{*}$ & $.39^{*}$ & -.25 \\
IL-6 & .04 & $-.32^{\dagger}$ & .26 & -.29 \\
\hline \hline
\end{tabular}

${ }^{* *} p<.01 .{ }^{*} p<.05 .{ }^{\dagger} p<.10$

direction). Home chaos was unrelated to emotion regulation or effortful control. There were no sex differences.

\section{DISCUSSION}

We examined hormones relevant for regulating nutrient intake and metabolism, as well as learning and memory, and pro-inflammatory cytokines, in a pilot study of lowincome preschoolers. Replicating findings in older children (Antunes, Santos, \& Carvalho, 2009; Falorni et al., 1997; Salbe et al., 1997), we found leptin was positively associated with BMIz, and greater in females than males. We also detected associations of pro-inflammatory cytokines with leptin and the gut-derived hormones ghrelin and GLP-1. The co-regulation of metabolic and inflammatory factors suggests a common biological mechanism may drive production of gut hormones and cytokines, consistent with our hypothesis. That we detected this convergence in early childhood is notable; studying these processes longitudinally may identify possible long-term effects of these co-regulated hormones on learning. We also found that leptin, TNF $\alpha$, and to a lesser degree IL- 6 and GLP-1, were associated with better emotion regulation skills, but not with effortful control or home environment stress. We discuss below future research directions and implications for obesity prevention and school readiness.

We found some support for predictions in this pilot study-lower leptin levels were associated with negative 
lability, whereas higher leptin was associated with effective emotion regulation (e.g., using words to communicate emotions). One reason we found no associations with effortful control may be that effortful control is a broader construct than executive functioning, and leptin has been most consistently associated with specific executive function skills such as working memory (Labad et al., 2012; Lokken et al., 2009; Sellbom \& Gunstad, 2012), which we did not directly measure. Future work assessing discrete executive functioning skills would allow us to better understand these connections.

We also found some associations that were not predicted. Specifically, pro-inflammatory cytokines (TNF $\alpha$; IL-6 marginally), which have been associated with stress and depression in adults (Dowlati et al., 2010; Raison, Capuron, \& Miller, 2006), were related to better emotion regulation in our young sample. This finding is unexpected given that cytokines have been suggested as a mechanism through which early life stress can negatively affect biology and later stress regulation (Chen et al., 2006; Danese \& McEwen, 2012). Little is known about pro-inflammatory cytokines and emotion regulation in young children, however. That we found cytokines were associated with obesity-related biomarkers, which were similarly related to better emotion regulation, is intriguing and deserves further research attention. Illuminating connections among these different biological and behavioral systems in childhood is likely important for understanding how best to prevent obesity early in the lifespan, and perhaps also how to foster school readiness.

Notably, BMI was related only to leptin. One possible reason is that we measured all hormones at a single timepoint, and many of them change dynamically throughout the day (Froy, 2007). Also, BMI may not be a sensitive enough measure to detect subtle changes in fat tissue or metabolism associated with the hormones we examined (Daniels, 2009). Such associations may develop over time; overweight preschoolage children simply may not have been overweight/obese for a long enough period for links to become firmly established. Given the strong likelihood that children who are overweight by their preschool years will remain overweight or become obese (Nader et al., 2006), however, we might expect this association to emerge over time. The positive association between gut hormones and inflammatory cytokines has also not been observed previously. Overall, GLP- 1 and ghrelin are believed to have anti-inflammatory properties that counteract the effects of inflammatory cytokines (Baatar, Patel, \& Taub, 2011; Liu, Dear, Knudsen, \& Simpson, 2009; Liu, Hu, Simpson, $\&$ Dear, 2008). Previous studies have been conducted primarily in animals or in adults; mechanisms in children may operate differently. Longitudinal research designs with larger, more diverse samples would be greatly helpful in addressing these questions.

It is also important to emphasize that the gut hormones, adipokines, and pro-inflammatory cytokines discussed here in relation to obesity, learning, and mood are each governed by complex, transactional systems. The pathways we examined thus represent but a glimpse of the overall picture; we present this pilot investigation as a suggestive research direction. It will be important in future work to consider additional variables related to these processes. There is evidence, for example, that the physiological systems we examined are affected by stress exposure. Children may internalize effects of stress differently, with implications for health and development across domains. For example, leptin production can be stimulated by glucocorticoids, decreased in response to sympathetic activation, and decreased under conditions of chronic stress (Heiman et al., 1997; Sandoval \& Davis, 2003). Leptin can also inhibit cortisol production in response to acute stress (Bornstein, Uhlmann, Haidan, Ehrhart-Bornstein, $\&$ Scherbaum, 1997), and activate pro-inflammatory cytokines, contributing to low-grade inflammation (Otero et al., 2006). We did not find associations of these variables with our home environment stress measure, perhaps in part due to sample size, but also sample characteristics-although they were poor, children were not selected based on risks such as abuse or trauma, which should be considered when interpreting these pilot findings in light of the early life stress and health outcomes literature.

Finally, early childhood is a uniquely important period for developing school readiness skills (Blair \& Diamond, 2008), and also for preventing obesity (Daniels et al., 2005). Our findings suggest connections between physiological pathways relevant for obesity and potentially for learning. Understanding the physiological complexity that children bring to school settings is important for educators and others working with young children. Physiology, while not deterministic, can play a critical role in a child's preparedness to focus and engage in complex tasks. That obesity, cognition, and emotion regulation may have some common physiological pathways, and that biomarkers of these pathways can be initially identified in a young, lowincome cohort, illustrates the complex interplay of biology, environment, and development, and provides additional impetus to act to prevent childhood obesity. By doing so, we could reduce risk not only due to obesity-related psychosocial problems that may hamper school functioning (e.g., teasing, bullying), but also the biological sequelae of obesity that affect not only later health outcomes, but also potentially school readiness skills.

\section{CONCLUSION}

This unique data set afforded an investigation of obesityrelated biomarkers in a young, low-income sample, and an opportunity to consider associations between such biomarkers and school readiness skills. We hope this 
exploratory study might ignite discussion among researchers interested in stress, obesity and health, and development. We also cannot overstate the need to conduct this type of mechanistic work with an interdisciplinary research team. Each construct under investigation is governed by its own complex regulatory system and disciplinary-specific definition(s). Assembling teams of researchers interested in complementary overarching translational questions, who can transmit specialized knowledge to fellow investigators, is a vital preliminary step in moving from basic scientific discoveries to ultimately developing and testing biologically informed interventions to enhance developmental outcomes.

\section{REFERENCES}

Abbas, T., Faivre, E., \& Holscher, C. (2009). Impairment of synaptic plasticity and memory formation in GLP-1 receptor $\mathrm{KO}$ mice: Interaction between type 2 diabetes and Alzheimer's disease. Behavioural Brain Research, 205, 265-271. doi:10.1016/j.bbr.2009.06.035

Ahima, R. S., Bjorbaek, C., Osei, S., \& Flier, J. S. (1999). Regulation of neuronal and glial proteins by leptin: Implications for brain development. Endocrinology, 140, 2755-2762. doi:10.1210/en.140.6.2755

Andrews, Z. B. (2011). The extra-hypothalamic actions of ghrelin on neuronal function. Trends in Neurosciences, 34(1), 31-40.

Antunes, H., Santos, C., \& Carvalho, S. (2009). Serum leptin levels in overweight children and adolescents. The British Journal of Nutrition, 101, 1262-1266. doi:10.1017/S0007114508055682

Araki, S., Dobashi, K., Kubo, K., Kawagoe, R., Yamamoto, Y., Kawada, Y., ... Shirahata, A. (2008). Plasma visfatin concentration as a surrogate marker for visceral fat accumulation in obese children. Obesity, 16, 384-388. doi:10.1038/oby.2007.54

Atcha, Z., Chen, W. S., Ong, A. B., Wong, F. K., Neo, A., Browne, E. R., .. Pemberton, D. J. (2009). Cognitive enhancing effects of ghrelin receptor agonists. Psychopharmacology, 206, 415-427. doi:10.1007/s00213-009-1620-6

Baatar, D., Patel, K., \& Taub, D. D. (2011). The effects of ghrelin on inflammation and the immune system. Molecular and Cellular Endocrinology, 340(1), 44-58. doi:10.1016/j.mce.2011.04.019

Blair, C. (2002). School readiness: Integrating cognition and emotion in a neurobiological conceptualization of children's functioning at school entry. American Psychologist, 57(2), 111-127. doi:10.1037/0003-066x.57.2.111

Blair, C., \& Diamond, A. (2008). Biological processes in prevention and intervention: The promotion of self-regulation as a means of preventing school failure. Development and Psychopathology, 20, 899-911. doi:10.1017/S0954579408000436

Bornstein, S. R., Uhlmann, K., Haidan, A., Ehrhart-Bornstein, M., \& Scherbaum, W. A. (1997). Evidence for a novel peripheral action of leptin as a metabolic signal to the adrenal gland: Leptin inhibits cortisol release directly. Diabetes, 46, 1235-1238.

Carlini, V. P., Ghersi, M., Schioth, H. B., \&e de Barioglio, S. R. (2010). Ghrelin and memory: Differential effects on acquisition and retrieval.Peptides, 31,1190-1193. doi:10.1016/j.peptides.2010.02.021

Carlini, V. P., Martini, A. C., Schioth, H. B., Ruiz, R. D., Fiol de Cuneo, M., \& de Barioglio, S. R. (2008). Decreased memory for novel object recognition in chronically food-restricted mice is reversed by acute ghrelin administration. Neuroscience, 153(4), 929-934. doi:10.1016/j.neuroscience.2008.03.015

Chen, E., Hanson, M. D., Paterson, L. Q., Griffin, M. J., Walker, H. A., \& Miller, G. E. (2006). Socioeconomic status and inflammatory processes in childhood asthma: The role of psychological stress. Journal of Allergy and Clinical Immunology, 117, 1014-1020. doi:10.1016/j.jaci.2006.01.036

Chowen, J. A., \& Argente, J. (2011). Leptin and the brain. Hormone Molecular Biology and Clinical Investigation, 7, 351-360. doi:10.1515/hmbci.2011.113

Clayton, P. E., Gill, M. S., Hall, C. M., Tillmann, V., Whatmore, A. J., \& Price, D. A. (1997). Serum leptin through childhood and adolescence. ClinicalEndocrinology, 46,727-733. doi:10.1046/j.13652265.1997.2081026.x

Currier, M. B., \& Nemeroff, C. B. (2010). Inflammation and mood disorders: Proinflammatory cytokines and the pathogenesis of depression. Anti-Inflammatory and Anti-Allergy Agents in Medicinal Chemistry, 9(3), 212-220.

Dallman, M. F., Pecoraro, N., Akana, S. F., Fleur, S. E. L., Gomez, F., Houshyar, H., ... Manalo, S. (2003). Chronic stress and obesity: A new view of "comfort food". Proceedings of the National Academy of Sciences of the United States of America, 100(20), 11696-11701.

Danese, A., \& McEwen, B. S. (2012). Adverse childhood experiences, allostasis, allostatic load, and age-related disease. Physiology and Behavior, 106(1), 29-39. doi:10.1016/j.physbeh.2011.08.019

Daniels, S. R. (2009). The use of BMI in the clinical setting. Pediatrics, 124(Suppl 1), S35-S4l. doi:10.1542/peds.2008-3586F

Daniels, S. R., Arnett, D. K., Eckel, R. H., Gidding, S. S., Hayman, L. L., Kumanyika, S., ... Williams, C. L. (2005). Overweight in children and adolescents. Circulation, 111, 1999-2012. doi:10.1161/01.cir.0000161369.71722.10

Datar, A., \& Sturm, R. (2006). Childhood overweight and elementary school outcomes. International Journal of Obesity, 30, 1449-1460. doi:10.1038/sj.ijo.080331l

Davis, J. F. (2010). Adipostatic regulation of motivation and emotion. Discovery Medicine, 9(48), 462-467.

Diano, S., Farr, S. A., Benoit, S. C., McNay, E. C., da Silva, I., Horvath, B., ... Horvath, T. L. (2006). Ghrelin controls hippocampal spine synapse density and memory performance. Nature Neuroscience, 9 , 381-388. doi:10.1038/nnl656

Dowlati, Y., Herrmann, N., Swardfager, W., Liu, H., Sham, L., Reim, E. K., \& Lanctôt, K. L. (2010). A meta-analysis of cytokines in major depression. Biological Psychiatry, 67, 446-457. doi:10.1016/j.biopsych.2009.09.033

During, M. J., Cao, L., Zuzga, D. S., Francis, J. S., Fitzsimons, H. L., Jiao, X., ... Haile, C. N. (2003). Glucagon-like peptide-1 receptor is involved in learning and neuroprotection. Nature Medicine, 9 , 1173-1179. doi:10.1038/nm919

Elias, M. F., Sullivan, L. M., Wolf, P. A., \& D'Agostino, R. B. (2003). Lower cognitive function in the presence of obesity and hypertension: The Framingham heart study. International Journal of Obesity and Related Metabolic Disorders, 27, 260-268.

Evans, G. W., \& English, K. (2002). The environment of poverty: Multiple stressor exposure, psychophysiological stress, and socioemotional adjustment. Child Development, 73, 1238-1248. doi:10.1111/1467-8624.00469

Evans, G. W., \& Rosenbaum, J. (2008). Self-regulation and the income-achievement gap. Early Childhood Research Quarterly, 23, 504-514. doi:10.1016/j.ecresq.2008.07.002 
Falorni, A., Bini, V., Molinari, D., Papi, F., Celi, F., Di Stefano, G., ... Contessa, G. (1997). Leptin serum levels in normal weight and obese children and adolescents: Relationship with age, sex, pubertal development, body mass index and insulin. International Journal of Obesity and Related Metabolic Disorders, 21, 881-890.

Farooqi, I. S., \& O'Rahilly, S. (2009). Leptin: A pivotal regulator of human energy homeostasis. American Journal of Clinical Nutrition, 89, 980S-984S. doi:10.3945/ajen.2008.26788C

Farr, S. A., Banks, W. A., \& Morley, J. E. (2006). Effects of leptin on memory processing. Peptides, 27, 1420-1425. doi:10.1016/j.peptides.2005.10.006

Feese, M., Franklin, F., Murdock, M., Harrington, K., Brown-Binns, M., Nicklas, T., ... Morales, M. (2003). Prevalence of obesity in children in Alabama and Texas participating in social programs. Journal of the American Medical Association, 289, 1780-1781.

Fergenbaum, J. H., Bruce, S., Lou, W., Hanley, A. J. G., Greenwood, C., \& Young, T. K. (2009). Obesity and lowered cognitive performance in a Canadian First Nations population. Obesity, 17, 1957-1963. doi:10.1038/oby.2009.161

Flint, A., Raben, A., Astrup, A., \& Holst, J. J. (1998). Glucagonlike peptide 1 promotes satiety and suppresses energy intake in humans. Journal of Clinical Investigation, 101, 515-520. doi:10.1172/JC1990

Froy, O. (2007). The relationship between nutrition and circadian rhythms in mammals. Frontiers in Neuroendocrinology, 28(2-3), 61-71. doi:10.1016/j.yfrne.2007.03.001

Gable, S., Krull, J. L., \& Chang, Y. (2012). Boys' and girls' weight status and math performance from kindergarten entry through fifth grade: A mediated analysis. Child Development, 83, 1822-1839. doi:10.1111/j.1467-8624.2012.01803.x

Gallistl, S., Sudi, K. M., Aigner, R., \& Borkenstein, M. (2001). Changes in serum interleukin- 6 concentrations in obese children and adolescents during a weight reduction program. International Journal of Obesity and Related Metabolic Disorders, 25, 1640-1643.

Gregor, M. F., \& Hotamisligil, G. S. (2011). Inflammatory mechanisms in obesity. Annual Review of Immunology, 29, 415-445. doi:10.1146/annurev-immunol-031210-101322

Gundersen, C., Mahatmya, D., Garasky, S., \& Lohman, B. (2011). Linking psychosocial stressors and childhood obesity. Obesity Reviews, 12(5), e54-e63. doi:10.1111/j.1467-789X.2010.00813.x

Gunstad, J., Spitznagel, M. B., Keary, T. A., Glickman, E., Alexander, T., Karrer, J., . . J Juvancic-Heltzel, J. (2008). Serum leptin levels are associated with cognitive function in older adults. Brain Research, 1230, 233-236. doi:10.1016/j.brainres.2008.07.045

Halaas, J. L., Gajiwala, K. S., Maffei, M., Cohen, S. L., Chait, B. T., Rabinowitz, D., ... Friedman, J. M. (1995). Weight-reducing effects of the plasma protein encoded by the obese gene. [Research Support, U.S. Government, P.H.S.]. Science, 269(5223), 543-546. doi:10.1126/science.7624777

Harvey, J., \& Ashford, M. L. J. (2003). Leptin in the CNS: Much more than a satiety signal. Neuropharmacology, 44, 845-854.

Harvey, J., Shanley, L. J., O'Malley, D., \& Irving, A. J. (2005). Leptin: A potential cognitive enhancer? Biochemical Society Transactions, 33, 1029-1032.

Hassink, S. G., Sheslow, D. V., de Lancey, E., Opentanova, I., Considine, R. V., \& Caro, J. F. (1996). Serum leptin in children with obesity: Relationship to gender and development. Pediatrics, 98(2), 201-203.
Heiman, M. L., Ahima, R. S., Craft, L. S., Schoner, B., Stephens, T. W., \& Flier, J. S. (1997). Leptin inhibition of the hypothalamicpituitary adrenal axis in response to stress. Endocrinology, 9, 3859-3863.

Hoeman, L. D. (2007). The obese teen: The neuroendocrine connection. [Review]. The American Journal of Nursing, 107(2), 40-48.

Hosking, J., Henley, W., Metcalf, B. S., Jeffery, A. N., Voss, L. D., $\&$ Wilkin, T. J. (2010). Changes in resting energy expenditure and their relationship to insulin resistance and weight gain: A longitudinal study in pre-pubertal children (EarlyBird 17). Clinical Nutrition, 29, 448-452. doi:10.1016/j.clnu.2010.01.002

Jeffery, A. N., Murphy, M. J., Metcalf, B. S., Hosking, J., Voss, L. D., English, P., ... Wilkin, T. J. (2008). Adiponectin in childhood. International Journal of Pediatric Obesity, 3(3), 130-140.

Kaiser, A. P., Hancock, T. B., \& Cai, X. (2000). Parent-reported behavioral problems and language delays in boys and girls enrolled in Head Start classrooms. Behavioral Disorders, 26(1), 26-4l.

Kim, Y.-K., Jung, H.-G., Myint, A.-M., Kim, H., \& Park, S.-H. (2007). Imbalance between pro-inflammatory and anti-inflammatory cytokines in bipolar disorder. Journal of AffectiveDisorders, 104(1-3), 91-95. doi:10.1016/j.jad.2007.02.018

Kyrou, I., Chrousos, G. P., \& Tsigos, C. (2006). Stress, visceral obesity, and metabolic complications. Annals of the New York Academy of Sciences, 1083, 77-110. doi:10.1196/annals.1367.008

Labad, J., Price, J. F., Strachan, M. W. J., Deary, I. J., Seckl, J. R., Sattar, N., ... Edinburgh Type 2 Diabetes Study (ET2DS) Investigators. (2012). Serum leptin and cognitive function in people with type 2 diabetes. Neurobiology of Aging, 33, 2938-2941. doi:10.1016/j.neurobiolaging.2012.02.026

Lawson, E. A., Miller, K. K., Blum, J. I., Meenaghan, E., Misra, M., Eddy, K. T., ... Klibanski, A. (2012). Leptin levels are associated with decreased depressive symptoms in women across the weight spectrum, independent of body fat. Clinical Endocrinology, 76, 520-525. doi:10.1111/j.1365-2265.2011.04182.x

Li, X. L., Aou, S., Oomura, Y., Hori, N., Fukunaga, K., \& Hori, T. (2002). Impairment of long-term potentiation and spatial memory in leptin receptor-deficient rodents. Neuroscience, 113, 607-615.

Li, Y., Dai, Q., Jackson, J. C., \& Zhang, J. (2008). Overweight is associated with decreased cognitive functioning among school-age children and adolescents. Obesity, 16, 1809-1815. doi:10.1038/oby.2008.296

Liew, J. (2012). Effortful control, executive functions, and education: Bringing self-regulatory and social-emotional competencies to the table. Child Development Perspectives, 6(2), 105-11l. doi:10.1111/j.1750-8606.2011.00196.x

Liu, H., Dear, A. E., Knudsen, L. B., \& Simpson, R. W. (2009). A long-acting glucagon-like peptide-1 analogue attenuates induction of plasminogen activator inhibitor type- 1 and vascular adhesion molecules. The Journal of Endocrinology, 201(1), 59-66. doi:10.1677/JOE-08-0468

Liu, H., Hu, Y., Simpson, R. W., \& Dear, A. E. (2008). Glucagon-like peptide-1 attenuates tumour necrosis factoralpha-mediated induction of plasminogen [corrected] activator inhibitor-1 expression. The Journal of Endocrinology, 196(1), 57-65. doi:10.1677/JOE-07-0387

Lokken, K. L., Boeka, A. G., Austin, H. M., Gunstad, J., \& Harmon, C. M. (2009). Evidence of executive dysfunction in extremely 
obese adolescents: A pilot study. Surgery for Obesity and Related Diseases, 5, 547-552. doi:10.1016/j.soard.2009.05.008

Lumeng, J. C. (2009). Cortisol and eating behavior in low-income preschoolaged children. University of Michigan: National Institute of Diabetes and Digestive and Kidney Diseases (NIDDK).

Luppino, F. S., de Wit, L. M., Bouvy, P. F., Stijnen, T., Cuijpers, P., Penninx, B. W. J. H., \& Zitman, F. G. (2010). Overweight, obesity, and depression: A systematic review and meta-analysis of longitudinal studies. Archives of General Psychiatry, 67, 220-229. doi:10.1001/archgenpsychiatry.2010.2

Lutter, M., \& Elmquist, J. (2009). Depression and metabolism: Linking changes in leptin and ghrelin to mood. Faculty of 1000 Biology Reports, 1:63, August 2009. Retrieved from http://fl000.com/reports/b/1/63 doi:10.3410/Bl-63

Lutter, M., Sakata, I., Osborne-Lawrence, S., Rovinsky, S. A., Anderson, J. G., Jung, S., ... Zigman, J. M. (2008). The orexigenic hormone ghrelin defends against depressive symptoms of chronic stress. Nature Neuroscience, 11, 752-753. doi:10.1038/nn.2139

MacLusky, N. J., Cook, S., Scrocchi, L., Shin, J., Kim, J., Vaccarino, F., ... Drucker, D. J. (2000). Neuroendocrine function and response to stress in mice with complete disruption of glucagon-like peptide-1 receptor signaling. Endocrinology, 141, 752-762.

Maes, M. (1999). Major depression and activation of the inflammatory response system. In R. Dantzer, E. E. Wollman, \& R. Yirmiya (Eds.), Cytokines, stress, and depression (pp. 25-46). New York, NY: Kluwer Academic/Plenum.

Maletic, V., Robinson, M., Oakes, T., Iyengar, S., Ball, S. G., \& Russell, J. (2007). Neurobiology of depression: An integrated view of key findings. International Journal of Clinical Practice, 61, 2030-2040. doi:10.1111/j.1742-1241.2007.01602.x

Martos-Moreno, G. A., Kratzsch, J., Korner, A., Barrios, V., Hawkins, F., Kiess, W., \& Argente, J. (2011). Serum visfatin and vaspin levels in prepubertal children: Effect of obesity and weight loss after behavior modifications on their secretion and relationship with glucose metabolism. International Journal of Obesity, 35, 1355-1362. doi:10.1038/ijo.2010.280

Matheny, A. P., Jr., Wachs, T. D., Ludwig, J. L., \& Phillips, K. (1995). Bringing order out of chaos: Psychometric characteristics of the confusion, hubbub, and order scale. Journal of Applied Developmental Psychology, 16, 429-444. doi:10.1016/0193-3973(95)90028-4

McNay, E. C. (2007). Insulin and ghrelin: Peripheral hormones modulating memory and hippocampal function. Current Opinion in Pharmacology, 7, 628-632.

Metcalf, B. S., Jeffery, A. N., Hosking, J., Voss, L. D., Sattar, N., \& Wilkin, T. J. (2009). Objectively measured physical activity and its association with adiponectin and other novel metabolic markers: a longitudinal study in children (EarlyBird 38). Diabetes Care, 32, 468-473. doi:10.2337/dc08-1329

Moore, A. H., Wu, M., Shaftel, S. S., Graham, K. A., \& O'Banion, M. K. (2009). Sustained expression of interleukin-lbeta in mouse hippocampus impairs spatial memory. Neuroscience, 164, 1484-1495. doi:10.1016/j.neuroscience.2009.08.073

Morrison, C. D. (2009). Leptin signaling in the brain: A link between nutrition and cognition? Biochimica et Biophysica Acta, 1792, 401-408.

Nader, P. R., O'Brien, M., Houts, R., Bradley, R., Belsky, J., Crosnoe, R., ... for the National Institute of Child Health Human Development Early Child Care Research Network. (2006).
Identifying risk for obesity in early childhood. Pediatrics, 118 , e594-e601.

Nagy, T. R., Gower, B. A., Trowbridge, C. A., Dezenberg, C., Shewchuk, R. M., \& Goran, M. I. (1997). Effects of gender, ethnicity, body composition, and fat distribution on serum leptin concentrations in children. Journal of Clinical Endocrinology and Metabolism, 82, 2148-2152. doi:10.1210/jc.82.7.2148

Najman, J. M., Hayatbakhsh, M. R., Heron, M. A., Bor, W. O'Callaghan, M. J., \& Williams, G. M. (2009). The impact of episodic and chronic poverty on child cognitive development. The Journal of Pediatrics, 154, 284-289. doi:10.1016/j.jpeds.2008.08.052

Nauck, M. A., Vilsboll, T., Gallwitz, B., Garber, A., \& Madsbad, S. (2009). Incretin-based therapies: Viewpoints on the way to consensus. Diabetes Care, 32(Suppl 2), S223-S231. doi:10.2337/dc09-S315

Oomura, Y., Hori, N., Shiraishi, T., Fukunaga, K., Takeda, H., Tsuji, M., ... Sasaki, K. (2006). Leptin facilitates learning and memory performance and enhances hippocampal CAl long-term potentiation and CaMK II phosphorylation in rats. Peptides, 27, 2738-2749. doi:10.1016/j.peptides.2006.07.001

Otero, M., Lago, R., Gomez, R., Dieguez, C., Lago, F., Gómez-Reino, J., \& Gualillo, O. (2006). Towards a pro-inflammatory and immunomodulatory emerging role of leptin. Rheumatology, 45, 944-950. doi:10.1093/rheumatology/kell57

Parisi, P., Verrotti, A., Paolino, M. C., Miano, S., Urbano, A., Bernabucci, M., \& Villa, M. P. (2010). Cognitive profile, parental education and BMI in children: Reflections on common neuroendrocrinobiological roots. Journal of Pediatric Endocrinology and Metabolism, 23, 1133-1141.

Paz-Filho, G., Wong, M. L., \& Licinio, J. (2010). The procognitive effects of leptin in the brain and their clinical implications. International Journal of Clinical Practice, 64, 1808-1812. doi:10.1111/j.17421241.2010.02536.x

Perry, T. A., \& Greig, N. H. (2004). A new Alzheimer's disease interventive strategy: GLP-1. Current Drug Targets, 5, 565-571.

Porter, D. W., Kerr, B. D., Flatt, P. R., Holscher, C., \& Gault, V. A. (2010). Four weeks administration of Liraglutide improves memory and learning as well as glycaemic control in mice with high fat dietary-induced obesity and insulin resistance. Diabetes, Obesity and Metabolism, 12, 891-899. doi:10.1111/j.14631326.2010.01259.x

Putnam, S. P., \& Rothbart, M. K. (2006). Development of short and very short forms of the children's behavior questionnaire. Journal of Personality Assessment, 87(1), 102-112. doi:10.1207/s15327752jpa8701_09

Raison, C. L., Capuron, L., \& Miller, A. H. (2006). Cytokines sing the blues: Inflammation and the pathogenesis of depression. Trends in Immunology, 27(1), 24-31. doi:10.1016/j.it.2005.11.006

Raspopow, K., Abizaid, A., Matheson, K., \& Anisman, H. (2010). Psychosocial stressor effects on cortisol and ghrelin in emotional and non-emotional eaters: Influence of anger and shame. Hormones and Behavior, 58, 677-684.

Reinehr, T., de Sousa, G., \& Roth, C. L. (2007). Fasting glucagon-like peptide- $l$ and its relation to insulin in obese children before and after weight loss. Journal of Pediatric Gastroenterology and Nutrition, 44, 608-612. doi:10.1097/MPG.0b013e3180406a24

Reinehr, T., Kratzsch, J., Kiess, W., \& Andler, W. (2005). Circulating soluble leptin receptor, leptin, and insulin resistance before and after weight loss in obese children. International Journal of Obesity, 29, 1230-1235. doi:10.1038/sj.ijo.0803027 
Riggs, N. R., Spruijt-Metz, D., Sakuma, K. L., Chou, C. P., \& Pentz, M. A. (2010). Executive cognitive function and food intake in children. Journal of Nutrition Education and Behavior, 42, 398-403. doi:10.1016/j.jneb.2009.11.003

Roth, C. L., \& Reinehr, T. (2010). Roles of gastrointestinal and adipose tissue peptides in childhood obesity and changes after weight loss due to lifestyle intervention. Archives of Pediatrics and Adolescent Medicine, 164, 131-138. doi:10.1001/archpediatrics.2009.265

Salbe, A. D., Nicolson, M., \& Ravussin, E. (1997). Total energy expenditure and the level of physical activity correlate with plasmaleptin concentrations in five-year-old children. The Journal of Clinical Investigation, 99, 592-595. doi:10.1172/JCI119200

Sandoval, D. A., \& Davis, S. N. (2003). Leptin: Metabolic control and regulation. Journal of Diabetes and Its Complications, 17(2), 108-113.

Sellbom, K. S., \& Gunstad, J. (2012). Cognitive function and decline in obesity. Journal of Alzheimer's Disease, 30, S89-S95. doi:10.3233/jad2011-111073

Shaw, K. N., Commins, S., \& O’Mara, S. M. (2001). Lipopolysaccharide causes deficits in spatial learning in the watermaze but not in BDNF expression in the rat dentate gyrus. Behavioural Brain Research, 124(1), 47-54.

Shaw, K. N., Commins, S., \& O'Mara, S. M. (2005). Cyclooxygenase inhibition attenuates endotoxin-induced spatial learning deficits, but not an endotoxin-induced blockade of long-term potentiation. Brain Research, 1038, 231-237. doi:10.1016/j.brainres.2005.01.035

Shields, A., \& Cicchetti, D. (1998). Reactive aggression among maltreated children: The contributions of attention and emotion dysregulation. Journal of Clinical Child Psychology, 27, 381-395. doi:10.1207/s15374424jccp2704_2

Shin, J. Y., Kim, S. Y., Jeung, M. J., Eun, S. H., Woo, C. W., Yoon, S. Y., \& Lee, K. H. (2008). Serum adiponectin, C-reactive protein and TNF-alpha levels in obese Korean children. Journal of Pediatric Endocrinology and Metabolism, 21(1), 23-29.
Skinner, A. C., Steiner, M. J., Henderson, F. W., \& Perrin, E. M. (2010). Multiple markers of inflammation and weight status: Cross-sectional analyses throughout childhood. Pediatrics, 125 , e801-e809. doi:10.1542/peds.2009-2182

Smith, E., Hay, P., Campbell, L., \& Trollor, J. N. (2011). A review of the association between obesity and cognitive function across the lifespan: Implications for novel approaches to prevention and treatment. Obesity Reviews, 12, 740-755. doi:10.1111/j.1467789X.2011.00920.x

Soczynska, J., Kennedy, S., Woldeyohannes, H., Liauw, S., Alsuwaidan, M., Yim, C., \& McIntyre, R. (2010). Mood disorders and obesity: Understanding inflammation as a pathophysiological nexus. NeuroMolecular Medicine, 1-24. doi:10.1007/s12017-010$8140-8$

Squire, L. R. (1992). Memory and the hippocampus: A synthesis from findings with rats, monkeys, and humans. Psychological Review, 99(2), 195-231.

Steiger, A., Dresler, M., Schussler, P., \& Kluge, M. (2011). Ghrelin in mental health, sleep, memory. Molecular and Cellular Endocrinology, 340, 88-96. doi:10.1016/j.mce.2011.02.013

Taylor, V. H., \& MacQueen, G. M. (2010). The role of adipokines in understanding the associations between obesity and depression. Journal of Obesity(Article ID 748048). doi:10.1155/2010/748048

Yamada, N., Katsuura, G., Ochi, Y., Ebihara, K., Kusakabe, T., Hosoda, K., \& Nakao, K. (2011). Impaired CNS leptin action is implicated in depression associated with obesity. Endocrinology, 152, 2634-2643. doi:10.1210/en.2011-0004

Zhang, M., Zhao, X., Li, M., Cheng, H., Hou, D., Wen, Y., ... Mi, J. (2011). Abnormal adipokines associated with various types of obesity in Chinese children and adolescents. Biomedical and Environmental Sciences, 24(1), 12-21. 